\title{
SENSORY EXPLOITATION: \\ UNDERESTIMATED IN THE EVOLUTION OF ART AS ONCE IN SEXUAL SELECTION THEORY?
}

\author{
Jan Verpooten \\ Departement of Biology \\ University of Antwerp \\ Antwerp, Belgium \\ Mark Nelissen \\ Departement of Biology \\ University of Antwerp \\ Antwerp, Belgium
}

\section{Correspondence:}

Jan Verpooten

Departement of Biology

University of Antwerp

Belgium

tel. +32486676786

jan.verpooten@ua.ac.be 


\section{ABSTRACT}

In this paper we argue that sensory exploitation, a model from sexual selection theory, deserves more attention in evolutionary thinking about art than it has up until now. We base our argument on the observation that in the past sensory exploitation may have been underestimated in sexual selection theory but that it is now winning field. Likewise, we expect sensory exploitation can play a more substantial role in modeling the evolution of art behavior. Darwin's theory of sexual selection provides a mechanistic basis to explain the evolution of male display traits. This mechanistic approach has proven useful to developing hypotheses about the evolution of human art. Both Boyd and Richerson (1985) and Miller (1998, 1999, 2000, 2001) have applied an indirect-benefit model from sexual selection to the evolution of art behavior. We argue that the mechanistic possibilities sensory exploitation has to offer as a model have remained underexplored so far, so we propose a concept based upon it. From the sensory exploitation perspective it follows that exaptive exploitation of psychosensory biases is a primary force in the evolution of art production (notice that the use of a model from sexual selection does not imply art evolved as a sexual display - we only use it for its mechanism) and that the indirect-benefit model only provides secondary forces. Thus, sensory exploitation may operate alone under some conditions but usually secondary processes as a result of indirect benefits are expected to kick in. The concept of sensory exploitation will need to play a central role in articulating all of the existing hypotheses about art.

Keywords: sensory exploitation, sensory biases, evolution of art, sexual selection, mimicry, indirect benefits, signal evolution, cultural transmission, iconic representations 


\section{Introduction}

In this paper we argue that Sensory Exploitation (SE), a model from sexual selection theory, deserves more attention in evolutionary thinking about art than it has up until now. We base our argument on the observation that in the past SE may have been underestimated in sexual selection but that it is now winning field. Likewise, we expect SE can play a more substantial role in modeling the evolution of art behavior. To avoid any misunderstandings we would like to stress that using a model from sexual selection to address questions about the evolution of human art behavior does not in any way imply that art must have been evolved as a sexual display (nor does it exclude it either).

Why then use models from sexual selection theory to explain its evolution in the first place? In both art behavior (producing and experiencing art) and courtship behavior perception plays a crucial role and intraspecies signaling is important. That may be why some fascinating similarities exist between human art behavior and traits and behaviors that function in sexual selection (mating preferences and displays) in other organisms. Many male animals display colorful traits and engage in courting behaviors such as singing and dancing (Andersson 1994) with apparent similarities to human dance and music. Male bowerbirds even build and decorate bowers - experimenting with various decorations (mosses, ferns, orchids, snail shells, berries and bark) in various positions, rearranging them, combining them in clusters of uniform color. Regent and Satin Bowerbirds even use a wad of leaves or bark to paint their bower with regurgitated fruit residues. Darwin was aware of these similarities between human art behaviors and courtship and he did not believe they were a coincidence. Just like art is produced to appeal to our sense of beauty - as he and his contemporaries believed -, male sexual displays ${ }^{1}$ evolved because they appeal to the sense of beauty of females (Darwin1871 pp. 301-302): "When we behold a male bird elaborately displaying his graceful plumes or splendid colors before the female, whilst other birds, not thus decorated, make no such display, it is impossible to doubt that she admires the beauty of her male partner. ... Whether we can or not give any reason for the pleasure thus derived from vision and hearing, yet man and many of the lower animals are alike pleased by the same colors, graceful shading and forms, and the same sounds."

Darwin, however, must have been puzzled, considering this agreement in taste (both he and the peahen admire the splendid visual show of a displaying peacock), about the disagreement in taste between him and his Victorian contemporaries and the so-perceived 'disgusting tastes of the primitive societies' they encountered at that time (Darwin 1871). This conundrum still lies at the heart of questions about the evolution of the arts.

What part of our tastes and preferences is old and shared with other animals? What part is culturally influenced? How do these two parts relate to each other? And how do these preferences relate to the evolution of art? In spite of the exact answer to these questions, what is important here is that Darwin (1871) lay the fundaments for a mechanistic approach to the evolution of apparently aesthetic preferences and displays across species in general and the evolution of human art: the process of selection - either natural (Darwin 1859) or sexual (Darwin 1871).

In this paper we will focus on theories about the processes of sexual selection and the explanatory power they may have regarding the above questions about the evolution of human art. We will discuss two existing approaches and propose the concept of SE. One is by Miller $(1998,1999,2000,2001)$, who proposes that 
art may in fact quite literally has evolved as a sexual display. The other is by Boyd and Richerson (1985) who apply Fisher's runaway process (a classical model from sexual selection theory) to cultural level evolution, thus applying a sexual model to explain non-sexual, cultural processes. Our approach focuses on sensory sensitivities and the possible role of the mechanism of SE in the evolution of art. It differs in some crucial aspects from the existing models. But rather than yet another hypothesis, our proposal may provide a fundament on which existing hypotheses about art could be articulated (included those not based on sexual selection). First we will briefly review relevant sexual selection models (section 1). Then, we will discuss how these models, including SE, can be applied to explain the evolution of visual art (section 2). We will discuss the relative roles of the different models and make some suggestions for further research.

\section{Sexual selection theory}

To make our argument it is not necessary to provide a full overview of sexual selection theory. We will only focus on those models applicable to the evolution of art. These are the indirect-benefit model or the 'FisherZahavi model' (Eshel et al. 2000; Kokko et al. 2003) and SE (e.g. Ryan 1990, 1998). Both Boyd and Richerson and Miller use the former; our concept is based on the latter.

Mate choice is an important evolutionary process that imposes sexual selection on the other sex and accounts for spectacular traits and behaviors, such as the above-mentioned, that would otherwise remain unexplained by natural selection (Darwin 1871; Andersson 1994). Both the indirect-benefit model and SE describe the relation between mate choice and these traits and behaviors. For an insightful review of sexual selection models in general - much in this section is based on it - see Kokko et al. 2003.

\section{Indirect-benefit model}

The Fisher-Zahavi model is an indirect-benefit model of mate choice. Both so-called good genes selection hypothesis (or fitness indicator theory) and Fisher's runaway process fall within this category. Good genes selection hypothesis simply states that females choose partners based on indicators of genetic quality. The evolutionary logic behind this behavior is that they as such provide their offspring with good genes. Choosing good genes positively influences the viability of the offspring and increases the chances that the female's offspring reaches reproductive age. So female choice for indicator traits is indirectly selected by piggybacking on the directly naturally selected good genes (Fisher1930, formally demonstrated by Lande 1981). Closely related to good genes hypothesis is the handicap principle. It predicts the game-theoretic constraint that indicators must be costly to be reliable because if not they can be faked too easily (Zahavi 1975, 1991, 1997).

Thus, fitter males, and the females who preferentially mate with them, will have offspring that inherit the genes for both fitness and the mating preference. The resulting linkage disequilibrium between preference genes and male fitness favors the spread and elaboration of the preference by indirect selection. Fisher's insight, that the increased importance of attractiveness as a component of male fitness can drive the exaggeration of a male trait that signals fitness beyond its otherwise naturally selected optimum, is known as 
the 'Fisherian runaway' process. So long as the process is unchecked by severe counterselection (i.e. survival costs), it will advance with ever-increasing speed (Fisher 1930).

\section{Sensory Exploitation}

Selection operating directly on the psychosensory system in contexts other than mate choice may either maintain or drive changes in mating biases (Williams 1966; Sober 1984; West- Eberhard 1984, 1992; Ryan 1990, 1995, 1998; Ryan and Rand 1990, 1993; Ryan and Keddy-Hector 1992; Endler 1992; Arak and Enquist 1993, 1995; Shaw 1995; Dawkins and Guilford 1996; Endler and Basolo 1998; Autumn et al. 2002 ). To some extent mate choice may thus evolve 'exaptively' by a process variously known as SE (e.g. Ryan 1990, 1998), sensory drive (e.g. Endler 1992), pre-existing bias or sensory traps (e.g. Christy 1995). For example, across some populations of guppies the strength of attraction to orange objects in a non-mating context explains $94 \%$ of the inter-population variation in female mating preferences for orange male ornaments (Rodd et al. 2002). Thus female sensitivity to orange-colored food items may be at least as important to the evolution of female mating preferences for males with large orange spots as any direct and indirect benefits that more-orange males deliver to their mates. SE may do more than offer a quirky exaptive alternative for how mating biases and male display traits evolve. Whenever studying a biological trait within the darwinian framework it is important to distinguish between the selective forces that led to its origin, its evolution and the processes that maintain it (Fisher, 1930). The origin of mating biases and displays are relatively hard to explain with the indirect-benefit model (Arnqvist, 2006). SE, however, may provide the initial 'nudge' often required to initiate choice-display coevolution (Arak and Enquist 1995, Payne and Pagel 2000). Recent empirical research, and theoretical models, suggest that origin by SE has been widespread (Rodriguez and Snedden, 2004; Arnqvist, 2006).

Arnqvist (2006) distinguishes two classes of origins of sensory biases that - as we will show in the next section - are also useful when considering the evolution of art. First, females are adapted to respond in particular ways to a range of stimuli in order to, for example, successfully find food, avoid to become food for predators and breed at optimal rates, times and places. Such multi-dimensional response repertoires form a virtually infinite number of pre-existing sensory biases that are potential targets for novel male traits. These he names 'adaptive sensory biases.' Notice that male traits that result from exploiting these adaptive sensory biases are in fact 'mimics' 2 .

Second, pre-existing sensory biases need not be the direct result of selection. In theory, they can simply be incidental and selectively neutral consequences of how organisms are built (Ryan 1990; Endler and Basolo 1998). For example, artificial neural network models have shown that networks trained to recognize certain stimuli seem to generally produce various sensory biases for novel stimuli as a by-product (Enquist and Arak 1993, 1994; Arak and Enquist1993; Johnstone1994). Similarly, research in 'receiver psychology' (e.g. Guilford and Dawkins 1991; Ghirlanda and Enquist 2003) have also suggested that higher brain processes may incidentally produce pre-existing sensory biases for particular male traits. Following Arak and Enquist (1993), Arnqvist (2006) refers to such sensory biases as 'hidden preferences.' These, then, can be seen as side effects or contingencies of how the sensory system, defined in its widest sense, of the receiver is constructed. Usually it results in abstract biases, for symmetrical or exaggerated 
traits for instance (Ryan 1998). In section 2 we will show that Arnqvist's (2006) dinstinction is very similar to the distinction Van Damme (2008) makes between 'aesthetics' and 'meaning' in describing art, suggesting that sensory bias theory could function as a suitable naturalistic approach to art.

All sensory systems have biases, and mating biases are therefore inevitable (Kirkpatrick and Ryan 1991, Arak and Enquist 1995). Of course, not all possible sensory biases are exploited in a mating context, although theoretically they could be. For instance, Burley (1988) showed that female zebra finches prefer males whose legs have been experimentally decorated with red or black plastic bands, while males with blue and green bands were rejected. Basolo (1990) showed that female platyfish prefer males with colorful plastic 'swords' glued on the ends of their tails, suggesting that this preference also pre-dated the evolution of such ornaments in their close relatives the swordtails. These could be called 'latent' preferences (Miller $2000,1998)$, preferences that are present but not exploited in a sexual context.

\section{Sensory Exploitation versus indirect-benefit model?}

The preceding discussion shows us how SE and indirect-benefits are generally considered to be intimately intertwined in determining the evolution of female biases and male display traits. For instance Kokko et al. (2003) write: "Even when a male trait has evolved to 'exploit' a pre-existing sensory bias, indirect selection on the female preference may occur owing to the benefits accruing from the production of more-attractive sons. Such a signal may potentially then become secondarily genetically correlated with other fitnessenhancing traits." But the use of the concepts 'fitness' and 'indirect benefit' are misleading. It can mean: good genes for survival and/or good genes for acquiring mates (attractivity). Consider the example of the orange spots in male guppies again. Kokko et al. 2003 suggest the evolution of orange spots could be mediated by indirect benefits. But are they also good genes for survival or just sexy son genes? It is quite possible that having orange spots does not correlate at all with genetic quality for viability. In that case, orange spots cannot and will not be selected as indicators of good genes for survival. This is an important observation, because it implies the possibility that evolution of male display traits may have more to do with the mechanism of SE than with female preferences for indicators of genetic quality for viability (see Fuller et al. 2005). The strong version of SE can thus be perceived as an alternative to the indirect-benefit model in sexual selection and some researchers have offered it as such. At least some of the sensory biases and displays we find in nature might be the result of SE alone (West-Eberhard 1984; Ryan 1990, 1998). We stress this possibility because it will be central in our argument in the next section that the strong version of the SE concept might offer an alternative model for the evolution of art.

\section{Biological mimicry}

In some cases it is clear that good genes selection and runaway processes can never happen, but that nevertheless impressive 'ornaments' evolve through signal evolution - that is in situations where benefits for the exploiter cannot in any way imply benefits for the signal-receiver. Some cases of biological mimicry fall within this category. For instance, in the genus Ophrys, plants evolved to attract male bees as pollinators by mimicking female mating signals. Here evolution by SE - the plants don't give any rewards in return - seems to be the only possible explanation (Schiestl and Cozzolino 2008; Jersakova et al. 2006). Of course, in this 
example indirect benefits don't apply because sensory biases of another species are exploited. But even intraspecies SE in a sexual context can occur without good genes for viability selection, as the following example illustrates. Many cichlid fish species independently evolved mouthbreeding as a highly specialized brood care behavior. Egg dummies, resembling the ova of the corresponding species, formed of various parts of the body can be found in different lineages of mouthbreeding cichlids. Most abundant are egg spots, which are conspicuously yellow spots on the anal fin of males. Females of mouthbreeding cichlids undoubtedly evolved sensory capabilities to detect eggs and are supposed to have a strong affinity for them, because they pick them up immediately after spawning. In fact, the ability to detect the eggs directly affects the female's fertility. Every missed egg results in a reduction in fitness. Consequently, a pre-existing sensory bias might have occurred in early mouthbreeders and might still occur in mouthbreeding species without egg dummies. As a consequence, males would have evolved egg spots in response to this sensory bias (Tobler 2006). After the female (receiver) has picked up her eggs (model), the male displays in front of her, showing the egg spots on his anal fin (mimic). The female responds to the life-like egg illusion by a sucking reaction and obtains a mouthful of sperm from the canny male in the process.

One of us (...) has performed quite some research on cichlids and has described the system of the egg spots (in Tropheus and Simochromis). During courtship males vibrate their body while showing the egg spots to the female. It could well be that by doing this they enhance the egg illusion, giving it a more three-dimensional effect in combination with the light-dark grading in color and the colorless outer ring the egg spots exhibit (e.g. Wickler, 1962).

It may be that the female's mating preference for a male with well-elaborated egg spots does not yield in any direct benefits for the female, nor any good genes for viability of the female's offspring. Runaway selection is also limited by the mimicking function of the egg spots: they may need to remain life-like in order to mislead the female. Thus this might well be an example of the strong version of SE. The female's preference may be solely maintained by exaptating the benefit of the detection of eggs after spawning (Tobler 2006). Interesting to the problem of the evolution of human representational art is that cases of mimicry, such as this one, show how ordinary selection via SE can produce two-dimensional representations (the egg spots) on a surface (the anal fin of the male) of three-dimensional objects (the eggs).

\section{Conclusions}

SE is a crucial addition to or possibly even an alternative - at least under certain conditions - to the indirectbenefit model to explain the evolution of signals used in sexual contexts. Likewise, as we will argue in the next section, it also applies to the evolution of art. A short summary.

- SE may provide the initial nudge for the evolution of male displays.

- SE may either maintain or drive changes in mating biases. As a result, male display traits may not necessarily be indicators of good genes for viability (i.e. survival).

- Cases of mimicry are clear-cut examples of the influence of SE as a mimic evolves to exploit sensory biases.

In section 2 we will show that a substantial portion of the discussion about the evolution of art is situated around the same questions as the ones covered in this section. We will thus use the summarized insights 
from this section to address them.

\section{Hypotheses about art}

Both Miller and Boyd and Richerson built their hypotheses upon the indirect-benefit model, although they do so in quite different ways. Especially the framework in which they apply the indirect-benefit model differs. Both their hypotheses are Darwinian, but Boyd and Richerson formalize the influence of culture into their models while Miller's model focuses on genes. Both approach art from a signal evolution perspective. There is a signaller (the producer of art), and a set of receivers (who perceive or experience the work of art).

\section{Miller's proposal}

Being an evolutionary psychologist, Miller $(2000,2001)$ considers the capacity to produce and appreciate art as a 'psychological adaptation': an evolved domain-specific mental capacity. Art as such serves a sexual function, as an extension, as Miller argues, of the human mind that itself evolved as a seducing device or an 'entertainment system' by sexual selection (Miller 2000). In Miller's view human art production is exactly like bowerbuilding by male bowerbirds. Females prefer to mate with males who construct larger, better quality, and more highly ornamented bowers (e.g. Borgia1995). The bower can be considered as the 'extended phenoytpe' of the male bowerbird (Dawkins, 1982): a genetically evolved, species-specific artefact constructed outside the individual's body, but very much in the service of the individual's genes. Like a bower, art is an aesthetic display that coevolved with aesthetic preferences (Miller 1998, 1999, 2000, 2001). It is an indicator of fitness. This means it is an indicator of reproductively important traits such as health, fertility, and genetic quality. "Perhaps beauty boils down to fitness" and "an art-work's beauty reveals an artist's virtuosity" (Miller 2001). Virtuosity, indicative of creative application of high skill and high intelligence, is such a fitness indicator (Miller 2001).

As Darwin (1871) noted, female animals are often choosier about their mates, and males often display more intensely than females. Accordingly, Miller (1999) identified a significant sexual dimorphism in cultural production (public paintings, books, music albums and plays). Miller explains this dimorphism with his 'cultural courtship model': human cultural (i.e. art) production functions largely as a courtship display, and the persistent sex difference in public cultural production rates reflects an evolved sex difference in courtship strategies (Miller 1999).

Critiques on Miller's proposal mainly focus on the last two points: the implied competitiveness for mates that drives art and the claim that the sexual dimorphism of art production that Miller perceived in recent western society can be universalized. Criticists stress the importance of tradition, that constrain individual competition and promote cooperation among group members in traditional societies (Coe 2003; Dissanayake 2001). They argue the majority of human visual art has been traditional and our perception is biased by an overemphasis on certain short periods where individual creativity and competitiveness were important, such as Renaissance (Coe 2003). The western non-traditional individualistic society of today is not representative but rather an exception. Moreover, if artists today are driven by competition, it is perhaps for media attention, 
not for mates. Another problem to Miller's proposal is that in traditional societies, females are sometimes the main producers of art (Dissanayake 2001; Coe 2003).

\section{Boyd and Richerson's proposal}

If traditions were important in human evolution, significantly constraining individual competition in favor of one's genes for instance, then it may be a good idea to incorporate culture, as a partly independent inheritance system from the genetic inheritance system, into the darwinian framework. This is what Boyd and Richerson (1985) dubbed 'Dual Inheritance Theory.' They pointed out that Darwin's theory does not explicitly distinguish cultural inheritance from genetic inheritance. Darwin was a self-declared Lamarckist who believed that acquired variation (through social learning for instance, a mechanism that transmits cultural information) played an important role in evolution (Richerson and Boyd 2001). So, Darwin's assumptions about beauty and evolution which we mentioned in the introduction, should be viewed within a genes culture coevolution framework.

Thus, within this framework darwinian selectionism is not exclusively applied to the genetic level but to both the genetic and cultural level. Also, how both inheritance systems interact in human evolution (i.e. 'genes culture coevolution') is investigated in a formalized manner (Boyd and Richerson 1985, 2005). Analogous to how population geneticists model the way different forces change gene frequencies in a population they model how forces interact to bias cultural transmission in a population - that is, how culture evolves. In Dual Inheritance Theory, the evolution and maintenance of cultures is described by several mechanisms including transmission bias. One of these mechanisms or forces is a certain type of transmission bias, namely 'indirect bias' - also called 'model bias' (Henrich and McElreath 2003; McElreath and Henrich 2007). Boyd and Richerson (1985, ch. 8) postulated that this force might cause a 'cultural runaway process' that in turn offers an explanation for the evolution of aesthetic traits and art. In short, individuals imitate successful people because they provide the highest chance of acquiring adaptive information (Flinn and Alexander1982). They prefer a certain value of an indicator of success (e.g. number of children or acres of land). This system of indicator trait and preference trait can, under certain conditions, be caught in a runaway process. A selfenforcing feedback loop between indicator and preference can cause the indicator trait which was initially an adaptive sign of success to become exaggerated following its own internal logic. "Much as peacock tails and bowerbird houses are thought to result from runaway sexual selection, the indirect bias runaway process will generate traits with an exaggerated, interrelated, aesthetically pleasing but afunctional form." (Boyd and Richerson 1985, p. 278).

As said, problematic in Miller's argument is the fact that women clearly also engage in art production, especially in traditional societies, which are the rule in human evolution, but also fairly recently in the emancipated west. If art evolved as a costly display of fitness, like a bowerbird's bower or a peacock's tail, one would expect no art production from females. Peahens and female bowerbirds are drab in color and the latter do not build bowers or any other aesthetic displays like their male counterparts do. Miller counters this problem by arguing that some form of mutual selection might operate. But when both males and females produce art - in other words, if costs are not covered by reproductive success - how then are the high costs of art borne which Miller assumes in the first place (Driscoll 2006)? Boyd and Richerson's model offers a 
possible way out of this problem:

"Notice that in the case of the cultural runaway process colorful displays are not as likely to be limited to the male sex as they are with the genetic analog. A prestigious male or female can have an unlimited number of cultural offspring by non-parental transmission, whereas in the genetic case only males can take advantage of multiple matings to increase their fitness enough to compensate for costly displays. The fact that women as well as men participate in elaborate symbolic behaviors is more consistent with a cultural than with a genetic runaway explanation" (Boyd and Richerson 1985, pp. 278-279).

This cultural hypothesis about art illustrates that application of sexual selection models to the evolution of art doesn't imply that art needs to have a sexual function. The model, in this case Fisher's runaway, is assumed to be applicable to non-sexual cultural transmission as well. However, we will argue, the concept of SE applied to art implies a runaway process - which is a secondary force resulting from indirect benefits as we have mentioned above - is not even required for aesthetics and art to evolve, exploitation of sensory biases a primary force - can do the trick just as well.

\section{Sensory Exploitation concept}

Our proposition is based upon the observation that both proposals show how sexual selection theory applied to art behavior offers valuable mechanistic insights into its evolution, but that they may underestimate the importance of SE in sexual selection and as such in the evolution of art. We will argue that SE may need to play a more substantial role in the evolutionary approach to art as it does so today in sexual selection theory. Art is believed to lie at the heart of culture, so if any behavior should be considered from a genes culture coevolution perspective, it must be art behavior. Thus, we will not apriori exclude the influence of cultural transmission from our model $4^{4}$.

Van Damme (2008, p. 30) describes art as follows: "Numerous contemporary definitions of the term 'art' mention in one way or another both 'aesthetics' (denoting say, high quality or captivating visual appearance) and 'meaning' (referring to some high quality or captivating referential content) as diagnostic features, although any clear-cut dinstinction between the two appears unwarranted, if only since there is no signified without a signifier." This description is very well suited for our evolutionary approach from the SE perspective. Notice that the distinction Van Damme makes between aesthetics and meaning roughly corresponds with the distinction Arnqvist (2006) makes between respectively hidden preferences influencing design of signals and adaptive sensory biases influencing content of signals resulting in mimicking signals. This will be important in the analysis of art as a result of exploitation of sensory biases.

Elaborating on the discussion in section 1, let us first consider the origin of art behavior. Pre-existing biases of the psychosensory ${ }^{5}$ system are the most plausible candidate for many of the origins of female mate preferences, influencing which male display traits will evolve (e.g. Arnqvist 2006). Analogously, human preexisting psychosensory biases may influence the direction in which art evolves. Our argument is that by focusing upon an indirect-benefit model this influence may be underestimated. For example, Miller (1998) argues against the sensory bias evidence that "... latent preferences are not necessary, according to R. A. Fisher's (1930) runaway theory. Even chance fluctuations in mate preferences, combined with a strange 
kind of evolutionary positive-feedback loop, could produce quite extreme mate preferences and quite exaggerated courtship traits." This argument is however easily reversed: why do you need to postulate a combination of chance fluctuations and a secondary process, such as Fisher's runaway when 'latent preferences' are inevitably present anyway (see Kirkpatrick and Ryan 1991, Arak and Enquist 1995)?" As mentioned, this critique also applies to Boyd and Richerson's runaway model. SE delivers a more parsimonious explanation for the origin and evolution of aesthetics - although it does not exclude secondary processes such as runaway. Miller $(1998,2000)$ also tends to minimize the sensory bias model by limiting it to preferences that are side effects of the sensory system (i.e. hidden preferences), ignoring adaptive sensory biases. That adaptive sensory biases influence the evolution of male traits is evidenced by clear-cut cases of mimics as sexual displays (Fuller et al. 2005). For instance consider the classical example used to explain Fisher's runaway process, the peacock's tail. Ridley (1981) suggested that tails with multiple eyespots, such as those of the peacock and the Argus pheasant, play upon a widespread responsiveness to eye-like stimuli in animal perception. In certain cases runaway is definitely limited by the need to maintain mimicking function.

The strong version of our concept predicts that SE not only exerts a substantial influence on the direction in which art evolves, but that it may also maintain art behavior. In section 1 we explained how this is theoretically possible in the evolution of male display traits. Analogously, this possibility applies to art production.

\section{$\underline{\text { Iconic representation }}$}

Just like sensory biases are useful to explain the design of signals in sexual selection (Endler 1992; Endler and Basolo 1998), these approaches are very useful to explain design aspects in art. Most sensory bias approaches to art focus exclusively on these hidden preferences (e.g. Hodgson 2006; Kohn and Mithen 1999; Ramachandran and Hirstein 1999). But these design generating biases do not explain content (i.e. meaning) of art nor do they provide as such a mechanistic explanation for the persistence of art behavior across cultures past and present.

Here we would like to explore the possibility of exploitation of adaptive sensory biases of which the resulting traits will be mimics. Mimics do have content or contain 'meaning.' Semioticists generally agree that biological mimicry is an example of iconicity in the natural world (for a review see Maran, 2007). We propose that it also works the other way around: iconic art are mimics evolved by SE. To the female cichlid we mentioned above both the signal from the egg as the signal for the egg spot means 'egg', in the sense that she responds indiscriminately towards both signals with a sucking reaction. In the same way, humans react towards art as iconic representations - even though we might 'know' it is an illusion - as if we react to the real thing. However, there is a difference between humans looking at art and the female cichlid looking at the egg spots. She really is deceived. We know we are looking at a painting of a landscape and not at the real thing. But does this distinction really matter?

Not really, because even though we know the movie or the novel, for instance, is not real, we are still very emotionally involved. Even though we might know it is fiction, we react as if it is not. Art exploits our visual system in the case of iconic representations and our emotions, regardless of the fact that we are aware of 
the distinction between fiction and reality. Human iconic representations are mimics and result from SE as well. As such, the mechanism of SE may be particularly interesting for modeling the origin, evolution and persistence of representational art or "iconic representations - the two- or three-dimensional rendering of humans and other animals, or to be more precise, the representation of things resembling those in the external world, or indeed imaginary worlds, fauna and flora especially, but also topographical features, built environments, and other human-made objects" (Van Damme, 2008). Just like cichlid egg spots exhibit both design features (color grading, transparent contour line, ...) and content or 'meaning' (to the female the egg spot means egg, see Maran 2007) as a consequence of SE, we hypothesize that iconic representations, such as rock art for instance, have evolved design and meaning through the same mechanism (paper submitted by the authors).

So, we suggest that the primary driving force underlying the origin and evolution of art such as iconic representations is exploitation of psychosensory biases. This doesn't exclude the forces of indirect-benefits like some form of good genes selection or Fisherian runaway process to occur. However, they will inevitably be secondary forces. This makes SE particularly suitable to articulate existing hypotheses about art (included those not based on sexual selection models). Art may be like religion: it is based upon some form of primary afunctional deception but it can nevertheless be both beneficial as malignant depending on the context and the secondary benefits involved.

\section{Self-exploitation}

Visual art is extra-corporal. A consequence of its extra-corporal aspect is that it is equally perceivable by its producers as by its receivers. When producers are also perceivers and possess more or less the same sensory system with comparable psychosensory biases, SE would predict they are equally prone to exploitation as any other receivers. In other words, same species SE via extracorporal traits implies the possibility of self-exploitation. Such a self-exploitation would be evidence that traits can be exploitative without any direct or indirect benefits. And it exists. Courting male fiddler crabs sometimes build mounds of sand called hoods at the entrances to their burrows. It was shown that burrows with hoods are more attractive to females and that females visually orient to these structures. Interestingly, a recent study showed that males themselves were also attracted towards their own hoods as a consequence of SE or sensory trap (Ribeiro, 2006). Hence, hood building causes self-exploitation. The same may apply to human visual art. As artists are always the first ones to perceive their artworks, they are most likely the first ones to be exploited by the signals they produce. Miller (2000) likes to use Picasso as an example of a successful artist, who produced a lot of paintings and had a lot of mistresses, to support his hypothesis that art evolved as a sexual display of good genes. But maybe Van Gogh, who hardly sold any paintings during his lifetime nor had a lot of success with women, to say the least, and locked himself in an attic so to speak to devote himself to his art - to self-exploit his psychosensory biases, is more exemplar of art behavior?

\section{Visual art production is genetically and/or culturally transmitted}

In Boyd and Richerson's (1985) cultural runaway model aesthetic traits are maintained as an afunctional side-effect of the otherwise adaptive indirectly biased cultural transmission. In Miller's model art production is maintained by the genetic reproductive success that compensates for its costs. In our SE concept both 
genetic and cultural selection for art production are possible, in principle. If visual art is seen as the exaptive materialisation of differential sensitivities based upon adaptive sensory biases and hidden preferences, then the persistence of its production can be both the result of genetic level selection and/or cultural level selection. If costs are bearable, or if any benefits (cultural/genetic) are involved, persistent psychosensory biases will bias genetic or cultural transmission. The impact of psychosensory biases will depend on several conditions (i.e. costs, benefits, context), but the upper limit is always the costs. The model predicts that the more costs can be borne, be it by direct benefits or by capacity of the population ${ }^{6}$, the more psychosensory biases will be materialized. There are some indications from the archeological record that iconic art production (figurative imagery, realistic art) is a mainly culturally transmitted behavior (paper submitted by the authors; also see Shennan 2001; Powell et al. 2009), while the ability to experience and interpret art is not and is in fact predating art production just like the origin of female sensory biases leading to mate preferences sometimes predate exploitation (e.g. Ryan 1998). The process of gradual accumulation of innovative skills and knowledge as a consequence of cultural "cumulative adaptive evolution" (Henrich 2004, Powell et al. 2009) also positively affects art production in the sense that it is less hindered by costs (i.e. elimination by natural selection), even when it may evolve in neutral or non-adaptive directions. This may have led to something that we might not always perceive of as art today, but that nevertheless plays upon a whole range of psychosensory biases, namely multimedia products such as movies, advertisement and videogames. These products of modern culture probably have more in common with cave art than cave art has with modern painting. As Marshall McLuhan said: "Ads are the cave art of the twentieth century." While these products are directed at exploiting emotional and visual sensitivities, modern art often is not. Its aim is rather conceptual, analyzing and 'deconstructing' its own underlying mechanisms. This distinction between modern art and rock art is one of the reasons the use of the term 'art' is tricky in a scientific approach. But, as we have hoped to show, a bio-evolutionary account of art is necessary and worthwhile as it provides a frame work in which ideas about more specific aspects of art can be articulated.

\section{Conclusion}

Darwin's theory of sexual selection provides a mechanistic basis to explain the evolution of male sexual display traits. This mechanistic approach has proven useful to developing hypotheses about the evolution of human art. Both Boyd and Richerson (1985) and Miller (1998, 1999, 2000, 2001) applied an indirect-benefit model to the evolution of art behavior. We have argued that the mechanistic possibilities SE has to offer have remained underexplored so far, so we proposed a concept based upon it. From the SE-perspective it follows that exaptive exploitation of psychosensory biases is a primary force in the evolution of art production and that the indirect-benefit model provides secondary forces. Thus, SE may operate alone under some conditions, but usually secondary processes as a result of indirect benefits are expected to kick in. When exactly these secondary processes will operate, should be further explored. Fuller et al. (2005) have suggested a number of tests to distinguish sensory exploitation from other preference models in sexual selection in practice. These tests can be used for the same purpose concerning the modeling of the evolution of art to further determine which relative roles models borrowed from sexual selection can play in clarifying 
the evolution of art behavior in humans. Although the concept of SE offers a primary force - a fundamental mechanistic basis underlying the evolution of art behavior - it does not exclude these other hypotheses, rather, it may enable to articulate them. "All of the major hypotheses about art will need to make use of the SE concept. Regardless of whether art is a byproduct or an adaptation, or what it is an adaptation for (e.g., mating display vs. group bonding), it will draw upon existing sensory sensitivities. This means that the concept of SE by itself does not lend support for any particular major hypothesis about art, but will need to play a central role in articulating all of them" (..., pers. comm.).

\section{Notes}

${ }^{1}$ We do not refer here to sexual male display that evolved as a consequence of intrasexual competition for mates, such as antlers (Andersson, 1994).

${ }^{2}$ The term 'mimic' usually refers to a whole, mimicking organism (e.g. Pasteur 1982), but Maran (2007, p. 237) - in our opinion usefully - argues from the semioticist viewpoint: "... neither the mimic nor

the model needs to be a whole organism but can be just a part of an organism both in spatial or temporal terms or just a perceptible feature." So here we use mimic in the latter sense.

${ }^{3}$ One could wonder why mainly women criticize Miller's hypothesis (e.g. Coe 2003, Dissanayake 2001, Driscoll 2006). A possible explanation of this 'female bias' might be the fact that there are a lot more female scientists today, just as there are more female professional artists.

${ }^{4}$ However notice that Dual Inheritance Theory does not exclude art to be sexually selected, for instance Boyd and Richerson (1985, chapter 8, p 277): "Cultural traits which affect mating preference could similarly affect genetic evolution through the action of sexually selection." Or Driscoll's (2006) 'cultural sexual selection hypothesis'

${ }^{5}$ The term 'psychosensory' is used here as a synonym for 'sensory' to stress that we do not only focus on hidden preferences but also on adaptive sensory biases - which often have a learned and emotional aspect, and a psychological, social and even cultural dimension.

${ }^{6}$ According to Boyd and Richerson (1985, p. 278) each culture may contain a number of afunctional or counterfunctional traits at equilibrium.

\section{Aknowledgements}

Many thanks to ... for their valuable comments.

\section{References}

Andersson, M. (1994). Sexual Selection. Princeton, New Jersey: Princeton University Press. 
Arak, A. \& Enquist, M. (1993). Hidden preferences and the evolution of signals. Philosophical Transactions of the Royal Society of London, Series B, 340, 207-213.

Arak, A. \& Enquist, M. (1995). Conflict, receiver bias and the evolution of signal form. Philosophical Transactions of the Royal Society of London, Series B, 349, 337-344.

Arnqvist, G. (2006). Sensory exploitation and sexual conflict. Phil. Trans. R. Soc. B, 361, 375-386.

Autumn, K., Ryan, M. J. \& Wake, D. B. (2002). Integrating historical and mechanistic biology enhances the study of adaptation. Quarterly Review of Biology, 77, 383-408.

Basolo, A. L. (1990). Female preference predates the evolution of the sword in swordfish. Science, 250, 808-810.

Borgia, G. (1995) Complex male display and female choice in the spotted bowerbird: specialized functions for different bower decorations. Animal Behavior, 49,1291-1301.

Boyd, R. \& Richerson, P.J. (1985). Culture and the Evolutionary Process. The University of Chicago Press.

Boyd, R. \& Richerson, P.J. (2005). The origin and evolution of cultures. The University of Chicago Press.

Burley, N. (1988). Wild zebra finches have band-color preferences. Animal Behavior, 36, 1235-1237.

Christy, J.H. (1995). Mimicry, Mate choice, and the Sensory Trap hypothesis. American Naturalist, 146, 171181.

Coe K (2003). The Ancestress Hypothesis: Visual Art as Adaptation. Rutgers University Press: New Brunswick, NJ.

Darwin, C. (1859). On the Origin of Species. [A facsimile of the first edition 1998.]. Cambridge, Massachusetts: Harvard University Press.

Darwin, C. (1871). The descent of man, and selection in relation to sex (2 vols.). London: John Murray. (Reprinted in 1952 by Encyclopedia Brittanica)

Dawkins, M. S. \& Guilford, T. (1996). Sensory bias and the adaptiveness of female choice. American Naturalist, 148, 937-942.

Dawkins, R. (1982). The extended phenotype: The gene as the unit of selection. Oxford, U.K.: W. H. Freeman. 
Dissanayake, E. (2001). Birth of the Arts. Natural History, Vol. 109, Issue 10.

Driscoll, C (2006).The Bowerbirds and the Bees: Miller on Art, Altruism, and Sexual Selection,Philosophical Psychology, 19:4,507 - 526

Endler, J.A. (1992). Signals, signal conditions, and the direction of evolution. American Naturalist, 139, S125S153.

Endler, J. A. \& Basolo, A. L. 1998. Sensory ecology, receiver biases and sexual selection. Trends in Ecology and Evolution, 13, 415-420.

Enquist, M. \& Arak, A. (1993) Selection of exaggerated male traits by female aesthetic senses. Nature 361, 446-448. (doi:10.1038/361446a0)

Enquist, M. \& Arak, A. (1994) Symmetry, beauty and evolution. Nature 372, 169-172.

(doi:10.1038/372169a0)

Eshel, I., Volovik, I. \& Sansone, E. 2000 On Fisher-Zahavi's handicapped sexy son. Evol. Ecol. Res. 2, 509523.Proc. Natl Acad. Sci. USA 96, 9169-9171.

Fisher, R. A. (1930). The Genetical Theory of Natural Selection. Clarendon Press. Oxford. cilia reticulata. Behav. Ecol. Sociobiol. 17, 199-205.

Flinn, M.V., \& Alexander, R.D. (1982). Culture theory: The developing synthesis from biology. Hum. Ecol. 10: 383-400.

Fuller R.C., Houle D., \& Travis J. (2005). Sensory Bias as an Explanation for the Evolution of Mate Preferences. American Naturalist, 166, 437-446.

Ghirlanda, S. \& Enquist, M. A. (2003) A century of generalization. Anim. Behav. 66, 15-36. (doi:10.1006/anbe.2003.2174)

Guilford, T., \& Dawkins, M.S. (1991). Receiver psychology and the evolution of animal signals. Animal Behavior, 42, 1-14.

Henrich, J. \& McElreath, R. (2003). The evolution of cultural evolution. Evolutionary Anthropology 12:123135.

Henrich, J. (2004). Demography and Cultural Evolution: How Adaptive Cultural Processes can 
Produce Maladaptive Losses: The Tasmanian Case. American Antiquity, Vol. 69, No. 2., pp. 197-214.

Hodgson, D (2006). Understanding the origins of Paleoart: The neurovisual resonance theory and brain functioning. PaleoAnthropology 2006: 54-67.

Jersakova, J., Johnson, S.D., \& Kindlmann, P. (2006). Mechanisms and evolution of deceptive pollination in orchids. Biol. Rev., 81, 219-235.

Johnstone, R. A. (1994) Female preference for symmetrical males as a by-product of selection for mate recognition. Nature 372, 172-175. (doi:10.1038/372172a0)

Kirkpatrick, M. \& Ryan, M. J. (1991) The evolution of mating preferences and the paradox of the lek. Nature 350, 33-38.

Kohn, M \& Mithen S. (1999). Handaxes: Products of sexual selection? Antiquity 73 (279): 518-26.

Kokko, H., Brooks, R., Jennions, M. D. \& Morley, J. 2003 The evolution of mate choice and mating biases. Proc. R. Soc. B 270, 653-664.

Lande, R. (1981). Models of speciation by sexual selection on polygenic traits. Proc. Natl Acad. Sci. USA 78, $3721-3725$.

Maran T (2007). Semiotic interpretations of biological mimicry. Semiotica 167-1/4 (2007), 223-248.

McElreath, R. \& Henrich, J. (2007). Dual inheritance theory: the evolution of human cultural capacities and cultural evolution. In R. Dunbar and L. Barrett, (Eds.), Oxford Handbook of Evolutionary Psychology Oxford: Oxford University Press.

Miller, G.F. (1998). How mate choice shaped human nature: A review of sexual selection and human evolution. In C. Crawford \& D. Krebs (Eds.), Handbook of evolutionary psychology: Ideas, issues, and applications. Lawrence Erlbaum, pp. 87-129.

Miller, G.F. (1999). Sexual selection for cultural displays. In R. Dunbar, C. Knight, \& C. Power (Eds.), The evolution of culture. Edinburgh U. Press, pp. 71-91.

Miller, G.F. (2000). The Mating Mind. London: Heinemann.

Miller, G.F. (2001). Aesthetic fitness: How sexual selection shaped artistic virtuosity as a fitness indicator and aesthetic preferences as mate choice criteria. Bulletin of Psychology and the Arts 1, special issue on Evolution, creativity, and art. 
Payne, R. J. H. \& Pagel, M. (2000). Inferring the origins of state-dependent courtship traits. Am. Nat. 157, $42-50$.

Powell A, Shennan S, Thomas, M G (2009). Late Pleistocene Demography and the Appearance of Modern Human Behavior. Science: 1298-1301.

Ramachandran, V. S., \& Hirstein, W. (1999). The science of art: A neurological theory of aesthetic experience. Journal of Consciousness Studies, 6,15-51.

Ribeiro, P. D., Christy J. H., Rissanen R. J., Kim T. W. (2006). Males are attracted by their own courtship signals. Behav Ecol Sociobiol 61:81-89.

Richerson, P J \& Boyd, R (2001). Built for Speed, Not for Comfort, Darwinian Theory and Human Culture, History and Philosophy of the Life Sciences, 23: 425-465

Ridley, M. (1981). How the peacock got his tail. New Scientist, 91, 398-401.

Rodd, F. H., Hughes, K. A., Grether, G. F. \& Baril, C. T. (2002). A possible non-sexual origin of a mate preference: are male guppies mimicking fruit? Proc. R. Soc. Lond. B 269, 475-481.

Rodriguez, R.L. \& Snedden, W. (2004). On the functional design of mate preferences and receiver biases. Animal Behaviour, 68, 427-432.

Ryan, M. J. (1990). Sexual selection, sensory systems and sensory exploitation. Oxford Surveys in Evolutionary Biology, 7, 157-195.

Ryan, M. J. (1995). Female responses to ancestral advertisement calls in tungara frogs. Science, 269, 390392.

Ryan, M.J. (1998, review 1999). Sexual Selection, Receiver Biases, and the Evolution of Sex Differences. Science Vol. 281. no. 5385, 1999 - 2003.

Ryan, M. J. \& Keddy-Hector, A. (1992). Directional patterns of female mate choice and the role of sensory biases. American Naturalist, Supplement, 139, 4-35.

Ryan, M. J. \& Rand, A. S. (1990). The sensory basis of sexual selection for complex calls in the tungara frog, Physalaemus pustulosus (sexual selection for sensory exploitation). Evolution, 44, 305-314.

Ryan, M. J. \& Rand, A. S. (1993). Sexual selection and signal evolution: the ghost of biases past. 
Philosophical Transactions of the Royal Society of London, Series B, 340, 187-195.

Schiestl, F P \& Cozzolino, S (2008) Evolution of sexual mimicry in the orchid subtribe orchidinae: the role of preadaptations in the attraction of male bees as pollinators BMC Evolutionary Biology 2008, 8:27doi:10.1186/1471-2148-8-27

Shaw, K. L. (1995). Phylogenetic tests of the sensory exploitation model of sexual selection. Trends in Ecology and Evolution, 10, 117-120.

Shennan S (2001) Demography and cultural innovation: a model and its implication for the emergence of modern human culture. Cambridge Archeol. J. 11: 5-16

Sober, E. 1984. The Nature of Selection. Evolutionary Theory in Philosophical Focus. Cambridge, Massachusetts: MIT Press.

Tobler M. (2006). Die Eiflecken bei Cichliden: Evolution durch Nutzung der Sinne? (The eggspots of cichlids: Evolution through sensory exploitation?). Zeitschrift für Fischkunde, Bd. 8 Heft 1/2, S. 39-46.

Van Damme W (1996). Beauty in context: Towards an anthropological approach to aesthetics. Philosophy of History and Culture 17. Leiden, New York, and Cologne: Brill.

Van Damme, W. (2008). Introducing World Art Studies. In Wilfried Van Damme \& Kitty Zijlmans (Eds), World Art Studies: Exploring Concepts and Approaches: Valiz.

West-Eberhard, M. J. 1992. Adaptation: current usages. In: Keywords in Evolutionary Biology (Ed. by E. F. Keller \& E. A. Lloyd), pp. 13-18. Cambridge, Massachusetts: Harvard University Press.

West-Eberhard, M. J. 1984. Sexual selection, competitive communication, and species-specific signals in insects. In: Insect Communication (Ed. by T. Lewis), pp. 283-324. London: Academic Press.

Wickler, W. (1962). 'Egg-dummies' as natural releasers in mouth-breeding cichlids. Nature, 194:1092-1093.

Williams, G. C. 1966. Adaptation and Natural Selection. Princeton, New Jersey: Princeton University Press.

Zahavi, A. (1975). Mate selection: A selection for a handicap. J. Theoretical Biology, 53, 205-214.

Zahavi, A. (1991). On the definition of sexual selection, Fisher's model, and the evolution of waste and of signals in general. Animal Behaviour, 42(3), 501-503.

Zahavi, A., \& Zahavi, A. (1997). The handicap principle: A missing piece of Darwin's puzzle. Oxford, UK: 
Oxford U. Press. 